\title{
Hour Times Picomole per Milliliter per Milligram
}

National Cancer Institute

\section{Source}

National Cancer Institute. Hour Times Picomole per Milliliter per Milligram. NCI

Thesaurus. Code C85641.

Hours times picomoles per milliliter per milligram. 